\title{
An investigation into tensile structure system: construction morphology and architectural interventions
}

\author{
Mohammad Arif Kamal
}

Architecture Section, Aligarh Muslim University, Aligarh, India. Corresponding Author: architectarif@gmail.com

Received: 29-08-2020

Accepted: 26-11-2020

\begin{abstract}
Tensile structures represent a new chapter in the history of building structures. Tensile structure system are capable of spanning large distances while incurring very little weight on supporting structure, developments in the design of fabric structure can dramatically change the ways in which permanent building construction is conceptualized. This paper reviews the current methods and systems for design and construction of fabric structures. The paper begins with a brief historical evolution and explanation of the various types of fabric structure that have previously been built. Subsequent topics address the development of computational analysis methods, innovative construction techniques, fabric material types, properties and their characteristics. In this paper, a qualitative descriptive evaluation research method has been used. The research methodology comprises of case studies, visual observation and data collection. Finally, five case studies around the world have been presented to validate and illustrate the various modern trends and the direct application of design and construction methods of tensile structure system.
\end{abstract}

Key words: tensile structure system, morphology, architectural interventions.

\section{Introduction}

A tensile structure is a construction of elements carrying only tension and no compression or bending. Tensile structures are the most common type of thin-shell structures. A tensile membrane structure is most often used as a roof, as they can economically and attractively span large distances. Most tensile structures are supported by some form of compression or bending elements, such as masts, compression rings or beams. Fabric structures are tensile structures in which a membrane is 'stretched' to form a threedimensional surface that can be used to create a roof, shading, or decorative component. Tensile structures have long been used in tents, where the guy ropes and tent poles provide pre-tension to the fabric and allow it to withstand loads. Steady technological progress has increased the popularity of fabric-roofed structures. The low weight of the materials makes construction easier and cheaper than standard designs, especially when vast open spaces have to be covered (Figure 1). However, not only could tension fabric be used as an effective roofing material for large spans, but its lightweight nature, translucent and reflective properties, and environmental adaptability could also be taken advantage in building construction (Wikipedia, 2019).

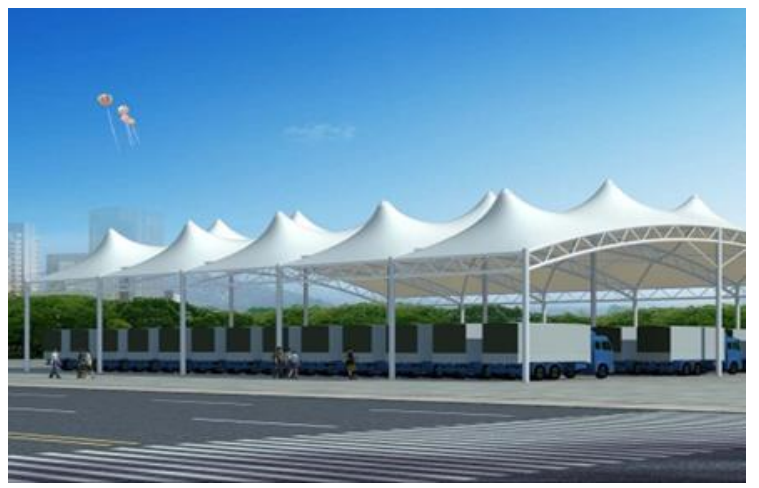

Fig 1. Tensile fabric structure for logistics center at Shenzhen, China. (Source: https://www.bdir.com/product/tensile-structure-for-logistics-center-tent-fabric-covered-roof) 


\section{Research Methodology}

In this paper qualitative analytical research method has been used. The research methodology comprises of case studies, visual observation and data collection. The systematic literature review has been explored through internet and secondary data from relevant published academic literature from journals articles and research papers. The data collection in the qualitative research are the data that comes from a number of case study examples that are described descriptively and are supported by illustrations and photographs to reinforce the arguments put forward. The basic concepts and backgrounds are investigated through literature and on-line media, observations to work for qualitative analysis conducted for tensile structure system to study the fabric architecture buildings, advantages, disadvantages, facades and the fabric future in construction field. Finally, five case studies around the world have been presented to validate and illustrate the direct application of design and architectural interventions of tensile structure system.

\section{Historical Evolution of Tensile Fabric Structures}

The origins of fabric structures can be traced back more than 44,000 years to the ice age and the Siberian Steppe, where remains have been found of simple shelters constructed from animal skins draped between sticks. From these purely functional origins however, the tent evolved over many centuries to become a symbol of frivolity. In the nineteenth and twentieth centuries, architects became inspired by technological breakthroughs in structural engineering and architectural theorising on an emerging functional aesthetic (Fabric, 2020). The Russian engineer Vladimir Shukhov was one of the first to develop practical calculations of stresses and deformations of tensile structures, shells and membranes (Figure 2). Shukhov designed eight tensile structures and thin-shell structures exhibition pavilions for the Nizhny Novgorod Fair of 1896, covering the area of 27,000 square meters.

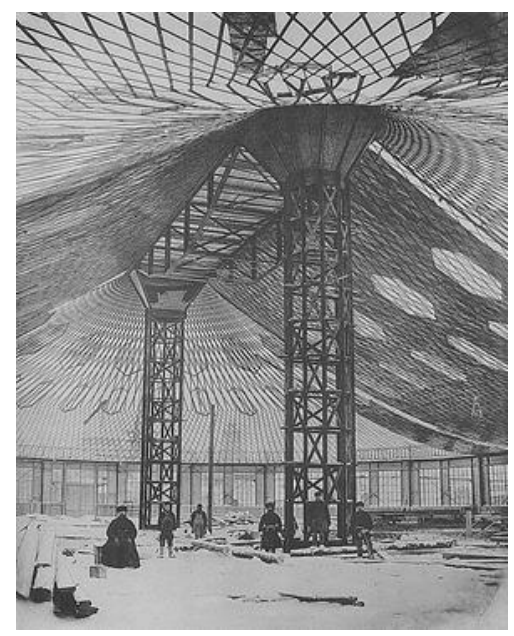

Fig 2. The first tensile steel shell of Oval Pavilion by Vladimir Shukhov. (Source:

https://en.wikipedia.org/wiki/File:Tensile_Steel_Lattice_Shell_of_Oval_Pavilion_by_Shukhov)

Antonio Gaudi used the concept in reverse to create a compression-only structure for the Colonia Guell Church. He created a hanging tensile model of the church to calculate the compression forces and to experimentally determine the column and vault geometries. The concept was later championed by German architect and engineer Frei Otto, whose first use of the idea was in the construction of the West German pavilion at Expo 67 in Montreal. Otto next used the idea for the roof of the Olympic Stadium for the 1972 Summer Olympics in Munich (Wikipedia, 2019). In the 1950s, architects and engineers began to take a renewed interest in using tension as the primary method of transferring loads in structures. Two main figures responsible for advancement in this investigation of tensile structures were Frei Otto and Horst 
Berger of Germany. The concept was later championed by German architect and engineer Frei Otto, whose first use of the idea was in the construction of the West German pavilion at Expo 67 in Montreal. Otto next used the idea for the roof of the Olympic Stadium for the 1972 Summer Olympics in Munich (Redskyshelters, 2020). Some current well known structures utilizing tension fabric include the foldable umbrella form tensile structure system in piazza in Medina, Saudi Arabia (Figure 3), the largest cable supported roof in the world of the Millennium Dome in London, England and the Haj Terminal in Jeddah, Saudi Arabia, designed in part by Berger and currently one of the largest tensile structures in the world (Midauser, 2020).

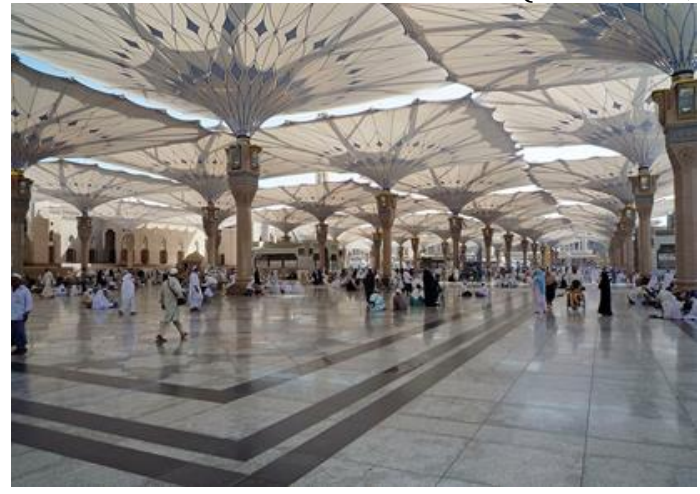

Fig 3. Foldable umbrella form tensile structure system in piazza in Medina, Saudi Arabia. (Source : https://en.wikipedia.org/wiki/File:Medina_Piazza_Umbrella.jpg)

\section{Concept Design and Criteria for Shape Finding}

There are two types of computer models for the concept design that can be used for investigating various fabric forms. They are summarised as below:

a) Wire frame computer models - these simple computer models are the starting point for investigating various fabric forms and developing the concept design into a practical form to ensure that the design criteria are satisfied.

b) Fully rendered computer models - models of the final design of the fabric structure can be added to the model of the whole building, and are thus very useful for final presentations to clients.

The concept design is the most important stage of the design process - a bad concept will reverberate throughout the design, manufacture and installation process, and will impair the appearance and performance of the final product. A number of factors need to be taken into consideration, including, but not necessarily limited to, the following:

a) Geometric constraints of the site and adjacent buildings

b) Sun shading levels required and sun angles

c) Air flow and ventilation of the space

d) Light transmission requirements for the space below

e) Availability and positions of anchorage points

f) Need for continuously sealed perimeter anchorages

g) Aesthetic considerations and compatibility with adjacent elements

h) Achievement of adequate curvature to minimise fabric stresses \& movements

i) Drainage of rainwater and avoidance of ponding

j) Suitable fabric slopes to ensure adequate self-cleansing

k) Nature of supporting structure and tensile elements 


\section{Shape and Forms of Tensile Structure System}

A two dimensional tension fabric membrane can take planar tensile forces, but it cannot take significant forces perpendicular to this plane. Therefore, in addition to being pre-stressed, tension fabric must take a certain three dimensional shape in order to remain stable (Figure 6). These shapes were discovered by Otto and Berger during their investigation of natural forms such as soap bubbles. There are two types of general shapes: anticlastic and synclastic shapes (Weaver, 2020). They are summarized as below:

Anticlastic shapes are created by having the radii of the principal curvatures on opposite sides of the tension fabric surface. As a result, when loaded at a particular point, tension will increase on one curve of the membrane and leave the opposite curve, thereby preserving equilibrium and keeping the structure stable. In order to keep anticlastic shapes, some kind of structural frame or support is necessary in the form of cables or steel beams. Some examples of anticlastic shapes are saddle, cone, and wave forms (Figure 4).

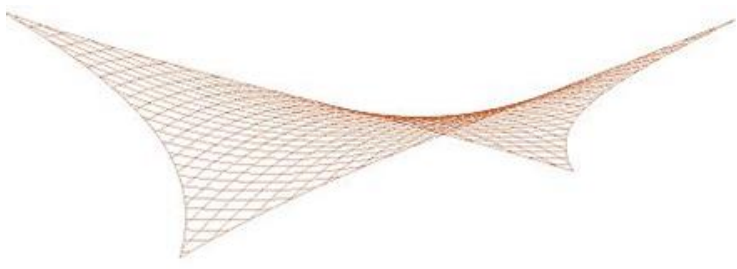

Fig 4. Example of anticlastic shape-saddle structure (Source: https://www.masterbuilder.co.in/morphologytensile-structure-systems/)

On the other hand, synclastic shapes are characterized by having the radii of the principal curvatures on the same side of the fabric (Figure 5). In order to counteract external forces, pressure from within is necessary. This is why synclastic shapes are associated with air inflated structures, as the difference of pressure created by air pumped into the building is able to counteract external forces in the form of wind or snow (Kamal, 2016).

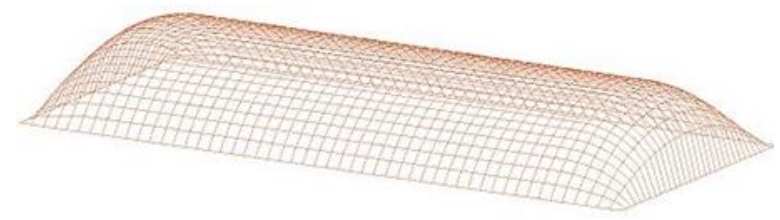

Fig 5. Example of synclastic shape-pneumatic structures (Source: https://www.masterbuilder.co.in/morphologytensile-structure-systems/]
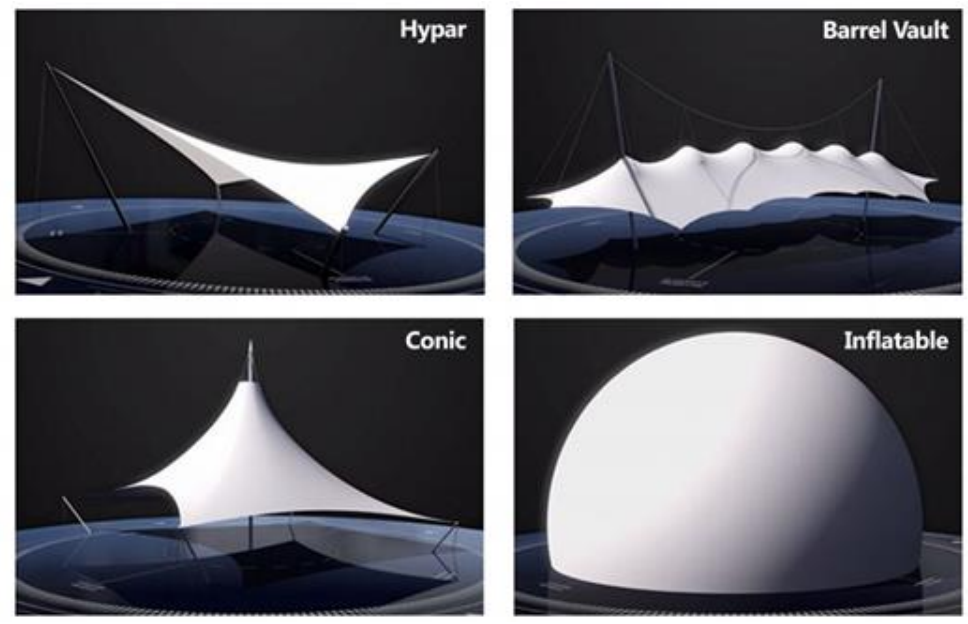

Fig 6. Different forms of tensile structures (Source: https://www.architen.com/articles/basic-theories-oftensile-membrane-architecture/) 


\section{Types of Tensile Structure System}

Membrane structures, encompassing both the tensioned fabric and the supporting structure, can span from 3 to 20 meters to spans more than 200 meters. For spans more than 200 meters, the fabric is supported by cables with steel or air so that unsupported span of the fabric is actually less than 30 meters. There are several systems adopted for tensioned fabric systems. While maintaining the concept of tension fabric design, each system is unique. These systems can be combined with each other to create interesting and even more complex designs. There are different types of tensile structure system, but generally there are five prominent types of tensile structure system (Armijos, 2020). They are summarized as below:

\subsection{Mast-supported systems}

In tensioned fabric structures where the supporting structure consists of masts, fabric is suspended from cables hung off masts or other compression elements. This kind of system is ideal for long span roofs. The masts must support both axial loading and lateral wind and dead loads (for angled masts). To resist buckling, which the masts are highly susceptible as a result of the axial forces increasing the moment stresses, the masts are constructed in lattices (Figure 7).

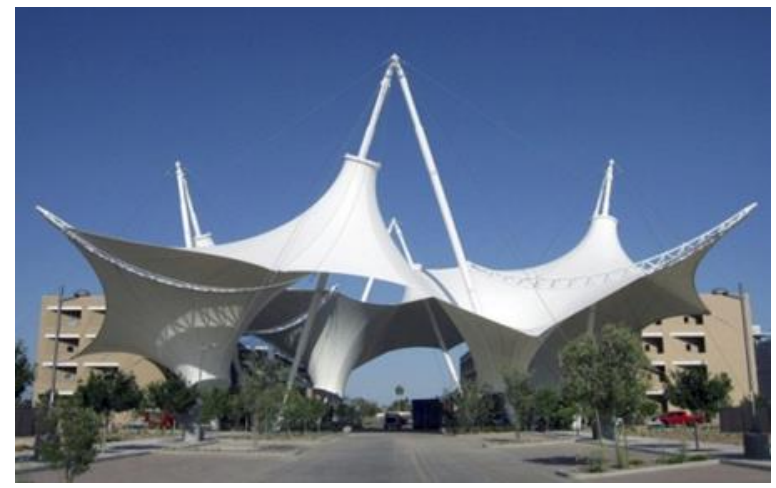

Fig 7. Mast supported tensile structure system (Source: https://www.archiexpo.com/prod/fabritecstructures/product-151879-1765809.html)

\subsection{Point-supported}

The point support tensile structure system has often hypar shaped (two high, two low connection points). It utilizes an exterior frame or series of peripheral masts. An example of primary point support structures is the simple cone structure that consists of a mast in the center of the membrane and can be repeated in groups to enclose a larger area of space. The existence of a big structural element in the center can also become obstructive (Figure 8).

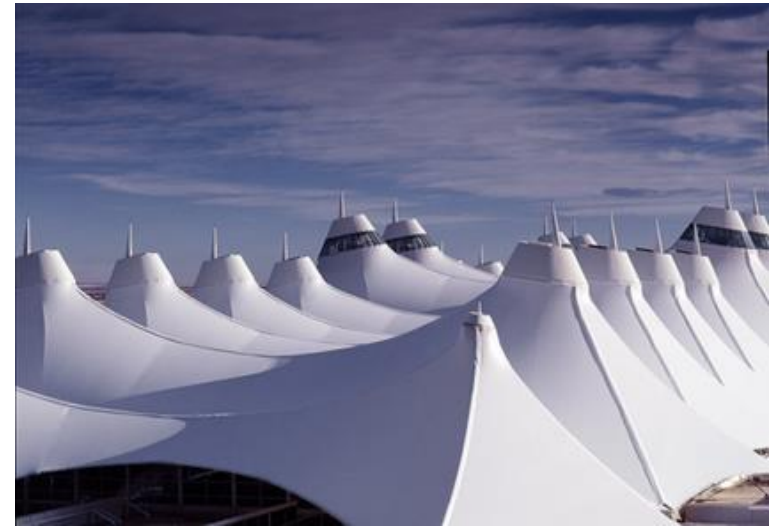

Fig 8. Point supported tensile structure system (Source: https://formfindinglab.files.wordpress.com/2016/11/dia.jpg?w=620) 


\subsection{Arch-supported}

The arch supported introduces a curved compression member. The cross arches often used for the frame. The arch-supported membrane shape is comprised of a saddle with one curving boundary and three straight boundaries. This configuration is conceptually very pleasing since the membrane work in complete tension while the arch is ideally working in complete compression (Figure 9). These systems can be designed quite efficiently for spans of about $8 \mathrm{~m}$.

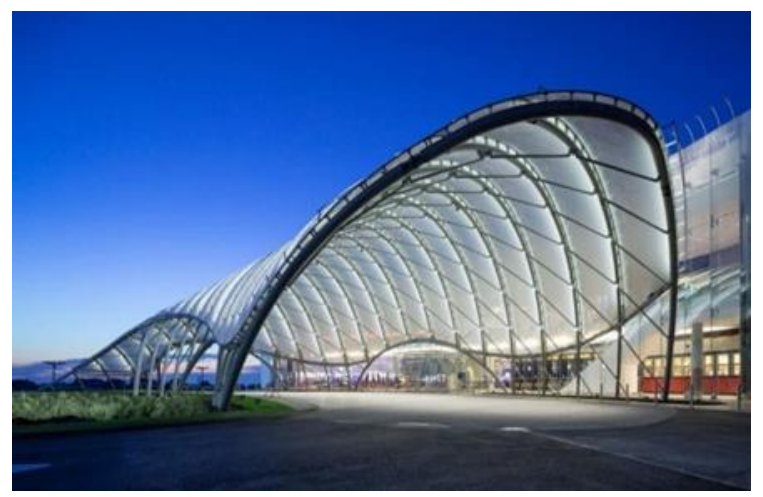

Fig 9. Arch supported tensile structure system (Source: https://parametrichouse.com/architecture-design-1$2 /)$

\subsection{Frame supported}

It is space framed. The Fabric is attached to a structural frame. The structural components carry all the forces. The Fabric is purely used as a cladding (Figure 10).

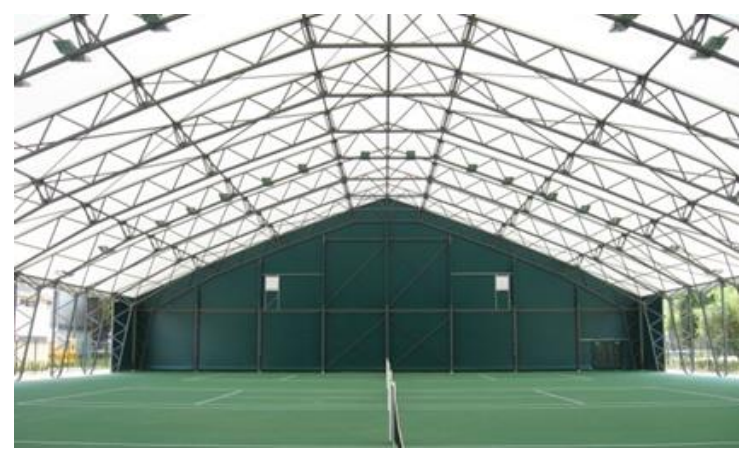

Fig 10. Frame supported tensile structure system (Source: https://veldemangroup.com/wpcontent/uploads/2016/05/SFS-Binnen-9.JPG.jpg)

\subsection{Simple Saddle/Hypar}

The hypar or saddle tensile structure systems have double curvature. They are generally 'saddle shape' and have two high points and two low points. In this type, the opposing directional forces that are introduced by prestressing the fabric in both directions counter balance each other. They also have the minimal surfaces. (Figure 11). 


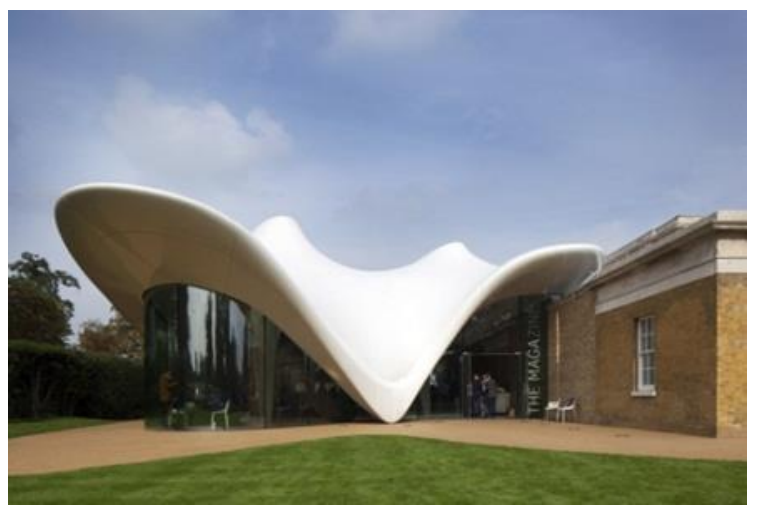

Fig. 11. Hypar tensile structure system of the Serpentine Sackler Gallery at London, UK. (Source: https://www.archdaily.com/433507/the-serpentine-sackler-gallery-zaha-hadid-architects

\section{Fabric Materials: Typology and Characteristics}

\subsection{PVC Fabric (PVC-Coated Polyester)}

The Poly Vinyl Chloride (PVC) fabric is less expensive than Polytetrafluoroethylene (PTFE) in material and processing, it has many virtues of soft texture and easy construction. But it is not as good as PTFE fabric in intensity, aging, fire-resistance etc. PVC fabric is made from polyester coated with PVC. The fabric that is commonly used in architecture is produced by the treatment of coating as applying several microns acrylic resin on the surface of PVC, which is in order to improve dirt-resistance. However, after a few years, PVC fabric will generally turn yellow, and is more likely to crack. Longevity of PVC fabric is 5-8 years according to different using surroundings. In order to improve weather protection of PVC fabric, fabric, which is coated fluoric resin on top of PVC, to improve its weather protection and dirt-resistance, has been under researches and development in recent years.

\subsection{PVDF}

PVDF is abbreviated of polyvinylidene fluoride. The material coating PVDF resin on PVC fabric surface is called PVDF. The difference between PVDF fabric and common PVC fabric is that the life span of PVDF is lengthened to 5-10 years.

\section{3. $P V F$}

PVF is abbreviated of polyvinyl fluoride.fabric is laminated with lamellate PVF on top of PVC fabric. Compared with PVDF, it is more wear-resistant and dirt-resistant. But it costs more than PVDF.

\subsection{PTFE Fabric (PTFE Coated Fiberglass)}

PTFE fabric is a material coated polyvinylidene fluoride on fiberglass textile. Comparing with PVC fabric, PTFE has great virtue of longevity, dirt-resistance and fire-resistance. However, high expense of material and processing, low flexility are the defects. In order to prevent fiberglass breaking, it requires a professional and complete plan in processing, folding, packing, construction techniques.

\subsection{Fabric options - PVC and PTFE}

There are three main types of tension fabric used in architectural applications today: PVC coated polyester, silicon coated fiberglass, and Teflon coated fiberglass. PVC coated polyester is the cheapest and easiest to manage of the three but also has the shortest life span. Teflon and silicon 
coated fiberglass are more durable, but are also more expensive (Browne, 2019). However, the basic structure of the material is similar for all three. The bottom layer of the tension fabric is a base fabric, usually made out of polyester or fiberglass. This fabric is created with fibers that run perpendicular, or in the warp and welt directions, and are weaved in and out of each other (Figure 12). The base fabric is extremely important as it dictates a number of the final fabric properties including stress and strain properties (how much force the fabric can take and how long it can stretch before failure) (Seaman, 2000). The Topcoats of protective fluorinated polymer lacquers (PVDF) applied to PVC coated polyester enhance its 'cleanability' and provide additional protection. In average climates, this fabric can last 15-20 years, or around 5 years less in sites where there is high exposure to sunlight. In addition to the incredible strength of the base fabrics, they are also relatively translucent and reflective. For example, Teflon coated fiberglass has a reflectivity of seventy per cent (Gandhi, 2020).

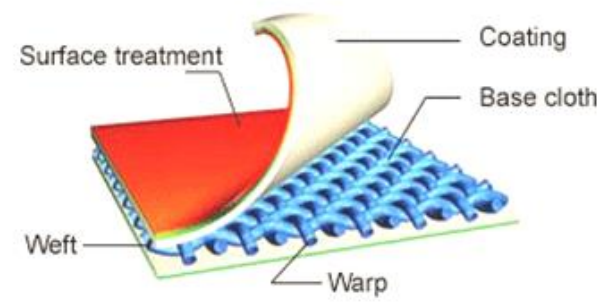

Component of Fabric

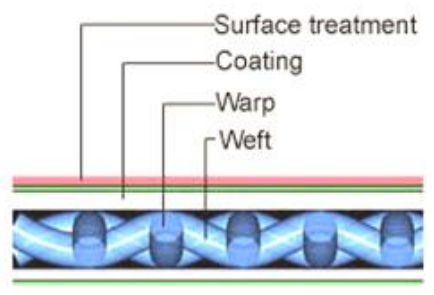

Section of Fabric

Fig 12. Section of Teflon coated fiberglass as tensile fabric material (Source: http://en.sztianfa.com/product.html)

\subsection{PVC / Polyester fabric}

PVC/Polyester fabric consists of a woven polyester base cloth, which is then coated with PVC and another top coating. They can be classified into 2 basic categories, depending on the type of protective top coating, as follows:

a) Acrylic lacquer

b) PVDF/acrylic lacquer alloy coatings in varying proportions

These top coatings have a large influence on the performance and appearance of the fabric, because they not only provide the fabric with some of its UV resistance, but they also vastly improve its self-cleaning characteristics. In general, fabrics with acrylic coatings have not performed that well long term in tropical countries, and most examples appear to attract and retain significant amounts of dirt and dust after relatively short times in service. On sites with high UV levels, the acrylic coatings break down fairly quickly, and thus the deterioration in appearance can occur within a few years after installation. The fabrics with PVDF/acrylic alloy coatings are the most commonly used, and have now been in service about 25 years. The PVDF/acrylic coating is heat-fused onto the base fabric as part of the manufacturing process. The top surface of the fabric has a smooth slippery feel, and it is thus very effective in repelling dirt and resisting mould growth. Useful lives of 15-25 years are achieved with these fabrics, with the anticipated life being directly proportional to the amount of PVDF in the top coating.

\subsection{PTFE / Fibreglass fabric}

The first outdoor PTFE/fibreglass structure was erected in California, USA 40 years ago and is still performing well in service. It is therefore likely that structures which are made with today's PTFE/fibreglass fabrics will achieve useful lives in excess of 50 years (Figure 13). PTFE/fibreglass fabric is very effective in repelling dirt and some structures which have been inspected after years in service have perfectly clean surfaces even though they have never had 
cleaning maintenance. Three of the new stadiums built for the Soccer World Cup in South Africa in 2010 had PTFE/fibreglass roofs, but the main disadvantage of PTFE fabric is its high cost - the overall cost of structures using this fabric are almost twice that of PVC structures.

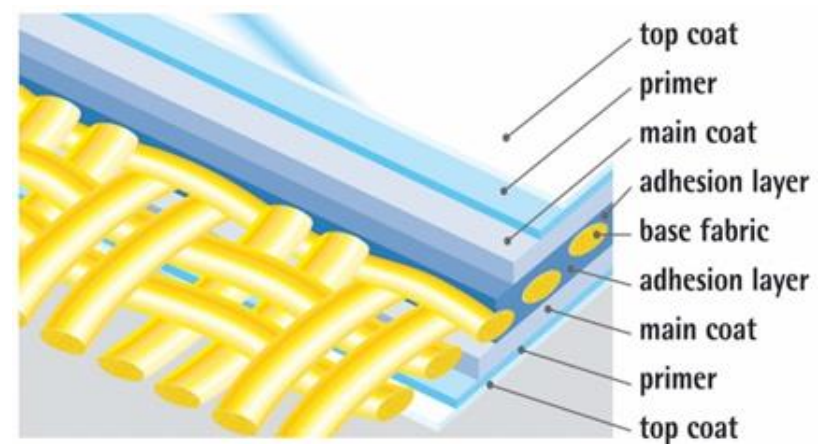

Fig 13. Different layers of fiberglass fabric material for tensile structures (Source: https://www.fabricgateway.com/topic/mehler+tensile\#\&gid=1\&pid=27)

\section{Construction System and Fabrication Details}

The constructor of fabric structures has a more important role to play than those of conventional structures, because they are dealing with relatively new materials, methods, and technologies. Indeed, fabric roof design is often considered so special that it falls under a separate contract from the main structural system of a building; clients will even sometimes appoint a different structural engineer for the fabric and for the main structure (Figure 14). More often than not, the design of fabric structure is limited by manufacturing capabilities. A fabric contractor must therefore be chosen with care. It is the responsibility of the fabricator to help architects and engineers in the material selection process, informing them of special material properties as well as advising them on practical patterning and pre-stressing techniques (Walter, 1977).

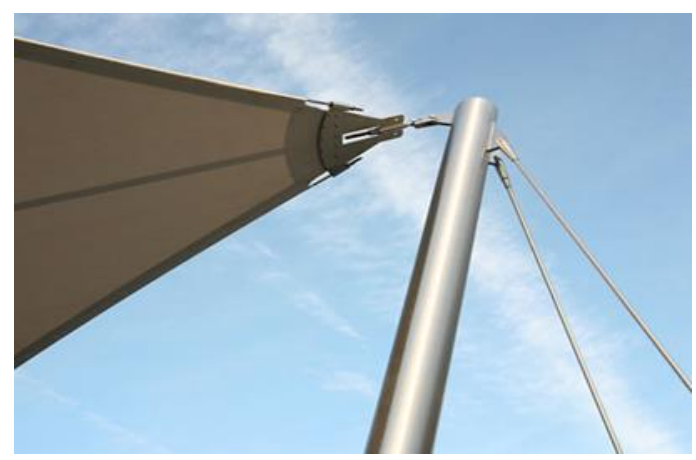

Fig 14. Connection details of fabric system with the mast (Source: http://fabricarchitect.com/componentsand-details.html)

\subsection{Types of connections}

The design of connections in fabric structures often requires careful and thorough consideration. Unlike connections in conventional buildings, they play a crucial role in the creation of architectural form and concept, as the geometry of a fabric roof is entirely dependent on the proper placement and design of these connections. They are often exposed to view and must therefore be constructed with aesthetics in mind. One of the most important considerations when designing fabric connections is the stress concentration that may occur in the local area surrounding it. Being highly sensitive to concentrated applied forces, clamps, cables, and seams should almost always fully develop stresses into the fabric. Fabric connections also need to be designed for load path, understanding that loads will tend to follow the stiffest path. In the case of a fabric membrane, applied loads will travel through the flexible membrane into less flexible 
interior or edge cables and then into the stiff and rigid supports (Figure 15). The following sections present various schemes for the connection of fabric elements (Shaeffer, 1996).

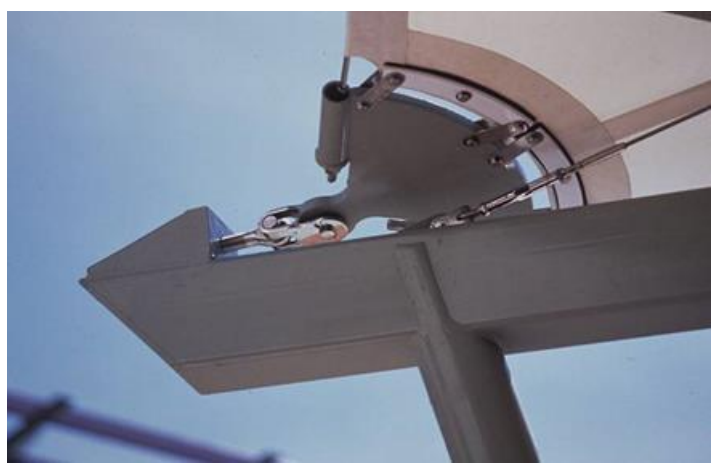

Fig 15. Corner plate end-connection of tensile membrane structure (Source : http://fabricarchitect.com/uploads/3/4/1/0/34108236/corner-plate-004_orig.jpg)

\subsection{Fabric to fabric}

After fabrics are patterned and cut, they can be joined together in a number of ways. These include heat sealing, gluing, and sewing. Lap seams are typically laid out in a "shingle" like pattern, with higher pieces of fabric draped over lower ones to facilitate water run-off (Figure 16). Seam strengths are dependent on coating adhesion and seam widths.

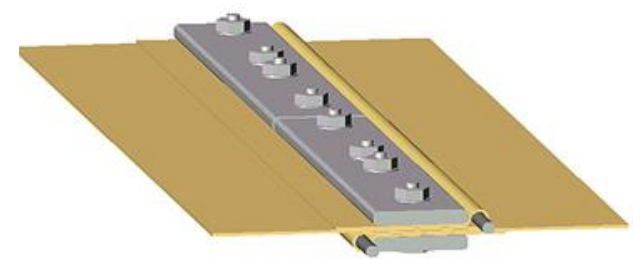

Fig 16. A standard lap seam joinery detail (Source: http://fabricarchitect.com/uploads/3/4/1/0/34108236/clamping-detail.jpg)

\subsection{Fabric to cable}

Fabrics to cable connections are needed when structural cables help to support a fabric membrane. One-sided connections are made when the fabric terminates at an edge cable and two-sided connections occur when the fabric is sectioned by the cable on both sides (Figure 17). Sectioning or subdividing fabric is usually done to facilitate the installation process. It also proves beneficial later for building maintenance and repair as fabric can be replaced one section at a time. Fabric to cable connections can be done in a few different ways. One method involves a cuff or sleeve, which uniformly transfers stress from the membrane into the cable or vice versa.

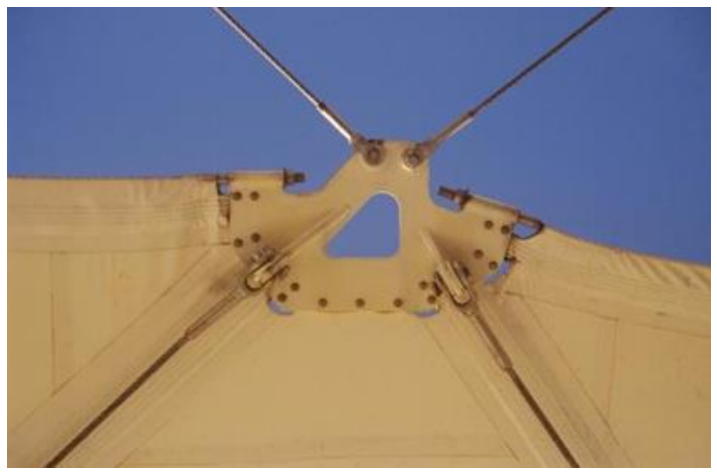

Fig 17. The fabric to cable connection details (Source: http://fabricarchitect.com/uploads/3/4/1/0/34108236/slides-030.jpg 
Another technique calls for the clamping down of a fabric roped edge. The roped edge will bear against the clamping hardware, which is attached to a base plate or rigid support (Figure 18). The clamping mechanism must be designed to distribute stresses evenly between the fabric edge and the fabric itself. They are rounded and padded to protect against unsupported stress concentrations.

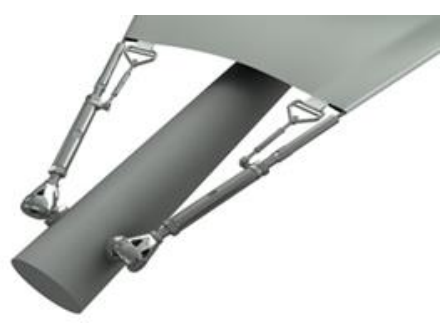

Fig 18. The edge detail of fabric to frame connection (Source: http://fabricarchitect.com/uploads/3/4/1/0/34108236/tennect-detail.jpg)

\subsection{Cable to cable}

Cable clamps and fixings like the ones in Figure 19 can be used to connect cables to other cables. These typically join single or double cables running in perpendicular directions, though turnbuckles and adjustable toggles will sometimes be used to splice cables going in the same direction. Although most cable end connections will develop the full strength of cable, they must be designed to account for both the breaking strength of cable and the capacity of the fitting.

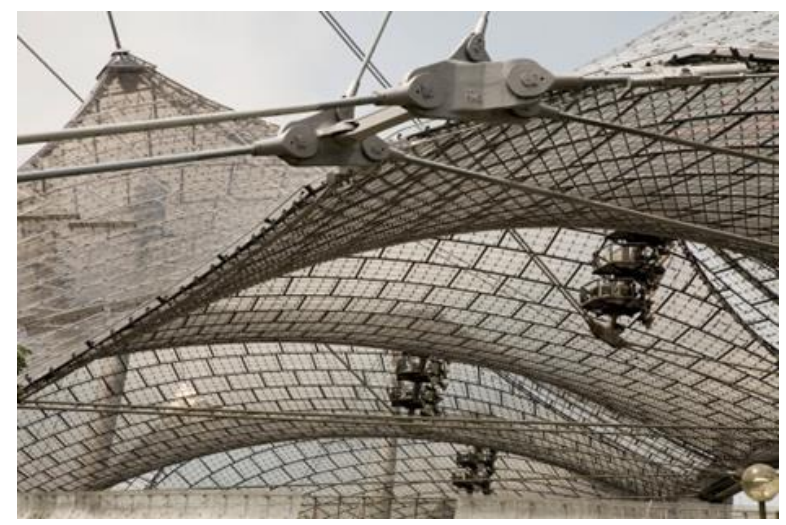

Fig 19. The cable to cable support connection details to prevent bending failure (Source: https://commons.wikimedia.org/wiki/File:Munich_-_Frei_Otto_Tensed_structures_-_5244.jpg)

\subsection{Anchorages}

The provision of adequate anchorages and supporting structures must be addressed at the earliest stages of the design process. Failure to address these issues early on could result in the tensile structures being impossible to include once the design and construction has progressed beyond a certain stage. Even small canopy structures impose significant forces on the substructures, and large structures will require special design features to be able to resist the tensile forces. Anchorages or mast-base connections are designed in much the same way as a column-base connection. The only difference here is that vertical masts will sometimes be free to rotate about the base. Fixed bases offer more stability during the erection and installation process and create a more rigid fabric roof system overall. However, rotating masts can be useful for fabric pre-stressing and rotating mast-base connections are generally cheaper than fixed bases, which require welding. Figure 20 illustrates a standard pinned mast fixing to the ground. 

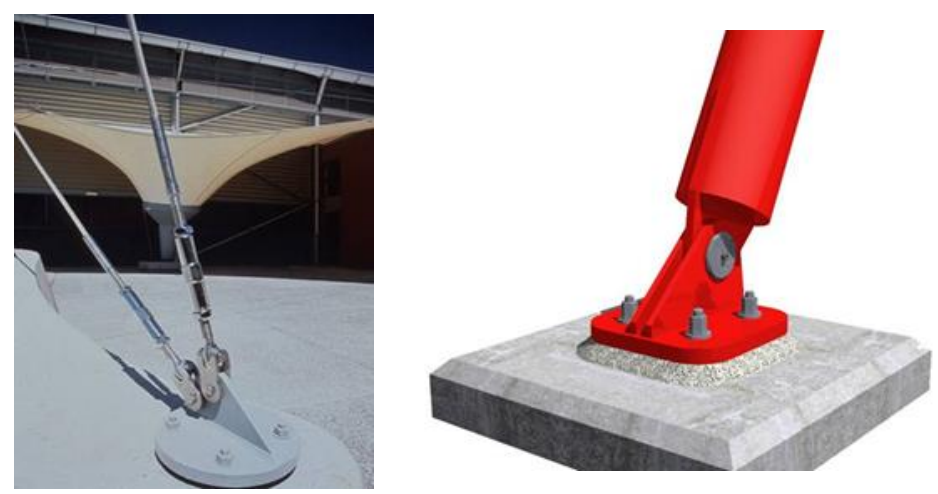

Fig 20. The anchorage detail of the base fixing at the ground (Source: http://fabricarchitect.com/uploads/3/4/1/0/34108236/red-base_orig.jpg)

\section{Performance Characteristics of Tensile Fabric System}

The observation of fabric structures in different situations in various parts of the world show that the particular environment in which the fabric is situated has a very significant effect on its performance (Tolani, 2016). The main factors which appear to influence the fabric performance are the following:

a) Geographic latitude and thus the temperature of the fabric

b) UV radiation level reaching the fabric

c) Humidity level

d) Pollution level, as well as the type of pollutants

e) Dust level

f) Frequency and nature of cleaning operations

g) Deposition of vegetable matter (leaves, etc.) onto the fabric

h) Staining resulting from rainwater run-off over other building materials

i) Exposure to direct rainfall to assist in dirt and dust removal

\subsection{Light and heat transmission}

One of the main advantages of fabric is its translucent properties - on average, architectural fabrics transmit about $13 \%$ of the light falling on the top surface. This results in a very pleasant light and airy feel to the space below, and can also result in significant cost savings on lighting. Fabric is also very effective in reducing the transmission of radiant heat from the sun, and it is a material which has been significantly underutilised in the climatic conditions prevailing in South Africa. However, global warming is likely to result in increased usage of tensile fabric structures in future.

\subsection{Fabric and fire}

Fire safety is a major factor in selection of membranes. These membranes are to be used as a medium to polarize sunlight and use it as an aesthetic formwork. PVC has fire retardant properties, and achieves a class 2 fire rating - meaning that the fabric is self-extinguishing and does not produce drips of molten fabric. This fire rating is generally accepted by most approval authorities for use as a roof enclosure. PVC has an added advantage in a fire situation in that the fabric seams will separate at about $100^{\circ} \mathrm{C}$, thus allowing the very early venting of toxic fumes and smoke. This is a major advantage in saving lives of people who may be trapped in the building. 


\subsection{Cleaning fabric}

Fabric is easy to clean and can be done using similar methods to those that one would use to clean a car, i.e. soft brushes, light duty, non-acidic detergents and copious rinsing water. Personnel can access the fabric by means of ropes and use soft soled shoes to walk on the fabric

\subsection{Lighting Design of fabric}

Lighting is very effective in emphasising the aesthetic appearance of fabric structures and should always be included whenever possible. Both back-lighting and front-lighting can be used depending on the effect that is desired.

\subsection{Cost Benefits}

There is a significant $50-60 \%$ cost benefit over conventional systems. The case study shows that the total cost of steel required for covering a specific area with space frame is found to be much greater than the cost of membrane used to cover the same area. The additional cost benefit is that membrane structures provide us with easy and efficient ventilation (both air as well as light) which in turn reduces the electricity bills.

\subsection{Lightweight Nature and Earthquake Resistance}

The weight of the membrane in tensile structures is very less and consequently, the quantity of structural steel utilized to support the membrane is also minimal. Thus, the weight as well as the overall cost of tensile structures is much less as compared to conventional roofing systems. As less steel is utilized, more useful space free of columns becomes available. As the weight of the structure is so little, it will not experience much acceleration forces under seismic action. As is evident from the above graphs it is found that the total reduction in steel consumption when using tensile structures as opposed to the conventional forms of the structures is about $50 \%$ $60 \%$ in each case.

\subsection{Low Maintenance}

In case of space frames, the major difference is of steel. The regular maintenance, such as painting, coating, etc. needs to be done, which sums up to be a considerable cost. While in case of membrane structure, membrane itself is resistant to corrosion. As the steel used is very at connections and supports that is the only part need to be taken care of. Also the self-cleaning membrane material can be used.

\subsection{Excellent Durability}

Weathering in polymer is a major concern and is definitively caused by the exposure to UV radiation, moisture, temperature, and humidity. The membrane material itself can withstand within the range of $-40{ }^{\circ} \mathrm{C}$ to $+70^{\circ} \mathrm{C}$. Companies of warranty for their fabrics and usually the minimum life span of these structures is about 25 years.

\subsection{Shortened Construction Schedules}

The erection of the tensile structures takes less than a week to complete as all the patterning and fabrication works are mostly carried out in warehouses and the structure is erected on site. The construction period is only the time required for its erection, which can be reduced to minimum by using advanced construction equipment. 


\subsection{Flexible Design Aesthetics}

Membrane structures can be designed, analysed and erected in any of the shape or form we require. It provides extra space for the designer to experiment with different shape. The membrane fabric can even incorporate an artificial lighting, which can add another aesthetic dimension to them.

\section{Case Studies}

\subsection{The $\mathrm{O}_{2}$ (Millennium Dome), London, $\mathrm{UK}$}

The 02 is a large entertainment district in South East London, England. It includes an indoor arena, a music club, a cinema, an exhibition space, piazzas, bars, and restaurants (Figure 21). It was built largely within the former Millennium Dome, a large dome-shaped canopy built to house an exhibition celebrating the turn of the third millennium (Wikipedia, 2020). The exhibition opened to the public on 1 January 2000 and ran until 31 December 2000; however, the project and exhibition was the subject of considerable political controversy and it did not attract the number of visitors anticipated, leading to recurring financial problems. In popular usage, the dome canopy is often still called The Dome, reflecting the substantial, and often adverse, publicity given to its building in the late $20^{\text {th }}$ century.

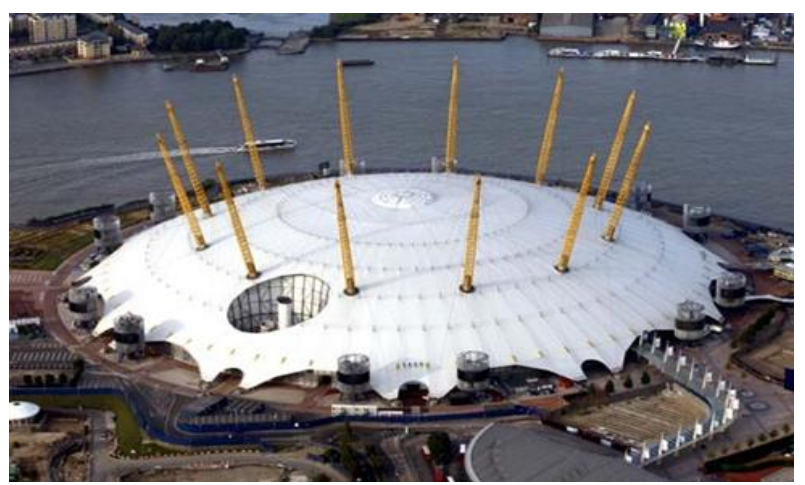

Fig 21. The exterior view of the Millenium Dome, London, UK (Source : static.independent.co.uk_Millenium Dome)

The 12 support towers represent the 12 hours, 12 months and 12 constellations of the sky. The Dome is 52 meters at its highest point, representing the 52 weeks of the year. Each span is 365 meters apart, symbolic of the numbers of days in a standard year. There are 24 scalloped edges at the base of the canopy, for each hour of the day. The Millennium Dome features twelve $100 \mathrm{~m}$ high steel masts that support a tensioned net of seventy kilometers worth of steel cables, arranged radially on the surface of the roof and held in place by hanger and tie down cables (Figure 22).

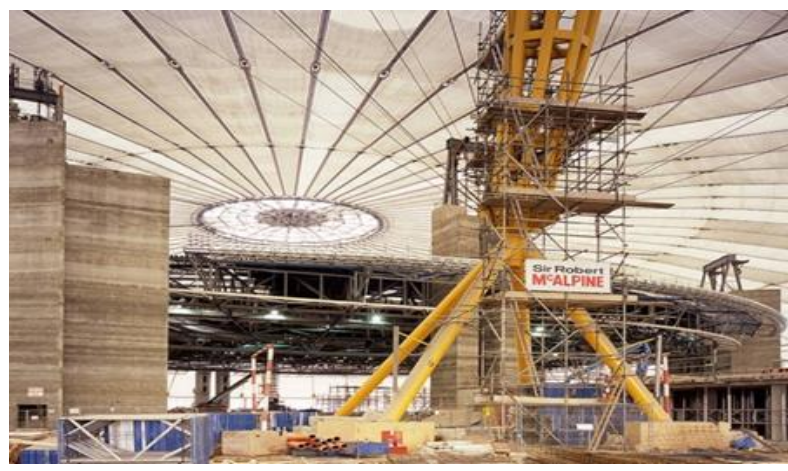

Fig 22. The interior view of the Millennium Dome at the time of installation (Source: https://www.srm.com/projects/o2-arena/) 
The canopy itself is a one millimeter white PTFE (polytetraflouroethylene) fabric with an interior lining designed to reduce thermal gain, and improve thermal and acoustic performance - in essence absorb both sound and condensation (Burohappold, 2020).

\subsection{Case Study 2: Denver International Airport, USA}

Denver International Airport, USA was completed in 1994 and is the World's third largest airport. The Teflon coated fibreglass roof of the airport is designed to resemble the peeks of the Rocky Mountains in winter, capped with snow (Figure 23). The tensile structure has stood the test of time and the structure hasn't completely failed under the extreme weather conditions that it experiences (Landrell, 2019).

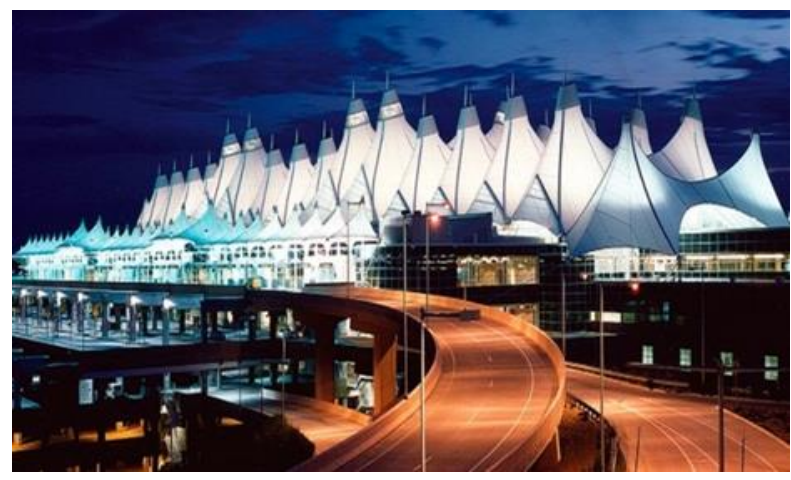

Fig 23. The exterior canopies of the Denver International airport, USA (Source: https://www.birdair.com/birdair-portfolio/denver-international-airport/)

The massive, 1,200- by 240-foot facility features a striking 'mountain range' canopy that utilizes Birdair's innovative steel cable systems and durable PTFE Teflon-coated fabric membrane. Punctuating this "ridge and valley" structure is a 900-foot atrium, known as the Great Hall, which rises to a height of 126 feet and welcomes visitors with an abundance of translucent, natural light. This graceful, lightweight roof incorporates two layers of fabric membrane to ensure proper sound control and sufficient insulation against Denver's demanding climate conditions. To support this load-bearing structure, 34 interior columns and 10 miles of steel cable were used, completely enclosing the building's exterior envelope. This design, in turn, provides travelers with adequate shade and protection. In addition, two separate exterior canopies extend the full length of the main building, serving vehicle ramps for in-bound and outbound passenger traffic while complementing the terminal's majestic design. In total, the Jeppesen Terminal roof required 375,000 square feet of tensile fabric membrane, with the adjacent curbside roofs requiring an additional 75,000 square feet (Figure 24). With such a large surface area, Birdair's design and engineering team optimized the sustainable benefits of PTFE fabric, which is chemically inert, highly resistant to dirt and pollution, and provides a long lifecycle with minimal maintenance (Birdair, 2019).

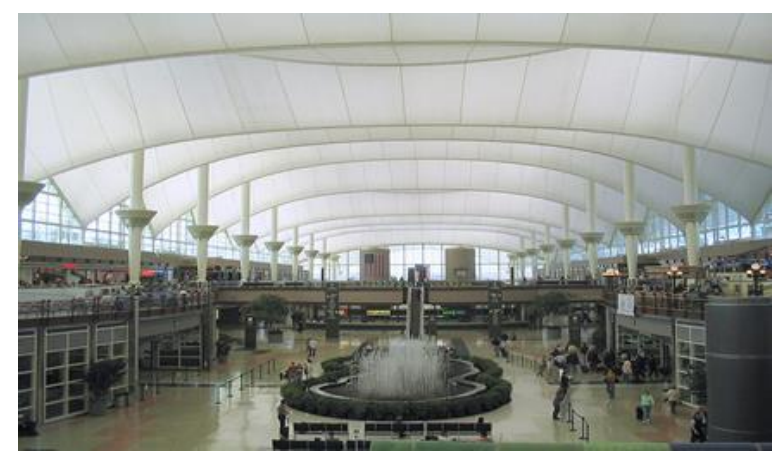

Fig 24. Tensile fabric membrane in the interior of Denver International airport, USA (Source: https://i.pinimg.com/originals/84/8d/a7/848da75c497cfe3b07d69220319f7482.jpg) 


\subsection{Case Study 3: Haj Terminal, Jeddah International Airport, Saudi Arabia}

In 1977 Skidmore Owens \& Merril, Architects (SOM) was commissioned by the government of Saudi Arabia to design a terminal at the International Airport in Jeddah to serve the pilgrims to Mecca during the annual Muslim pilgrimage (Haj). 80000 people a day had to be accommodated in transition between buses and airplanes. To protect people against the heat of the desert sun, $440000 \mathrm{~m}^{2}$ of space had to be covered. PTFE coated glass fiber fabric reflects $70 \%$ of the sun's heat, radiates out during the night, eliminates electric light because of its translucency. SOM chose a fabric structure concept which divides the building into 10 modules, each consisting of 21 tent units with a plan dimension of $45,75 \mathrm{~m}$ x 45,75 m. each module covers $320 \times 137 \mathrm{~m}$ (Figure 25). Two groups of five modules each are arranged along two sides of a central access road. 20 gates for the planes are located at the opposite ends of the modules. To keep the space below open, the structural concept by SOM's Fazlur Khan suspends the tent units from high masts which are located at the four corners of each tent. Interior supports consist of single columns. Along edges and corners two or four columns are combined into frames to resist the lateral forces. This arrangement of the support system gives the architecture of the world's largest roof its powerful image (Ishii, 1999).

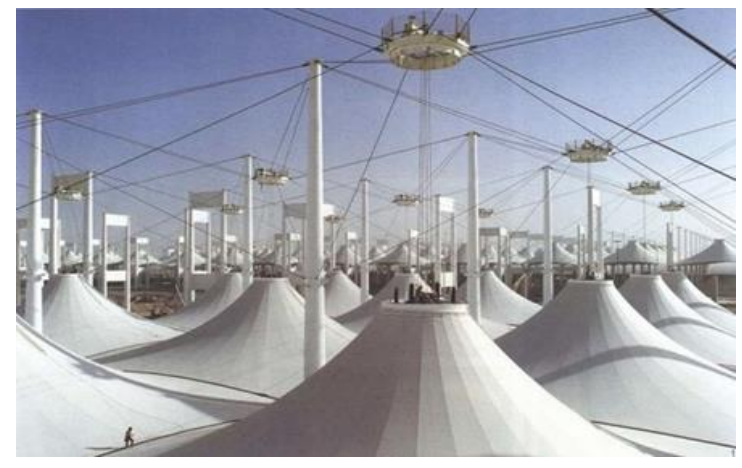

Fig 25. Tensile structure system of International airport at Jeddah, Saudi Arabia (Source: https://www.pinterest.fr/pin/376683956321452042/)

\subsection{Khan Shatyr Entertainment Center, Nur Sultan, Kazakhstan}

Khan Shatyr is a transparent tent located in Nur-Sultan, the capital city of Kazakhstan. Built in a neofuturist style, the architectural project was unveiled by the President of Kazakhstan Nursultan Nazarbayev on December 9, 2006 (Figure 26). The 150 metres high tent has a 200 metres elliptical base covering 140,000 square metres. Under the tent, an area larger than 10 football stadiums, is an urban-scale park, shopping and entertainment venue with squares and cobbled streets, a boating river, shopping centre, minigolf and indoor beach resort.

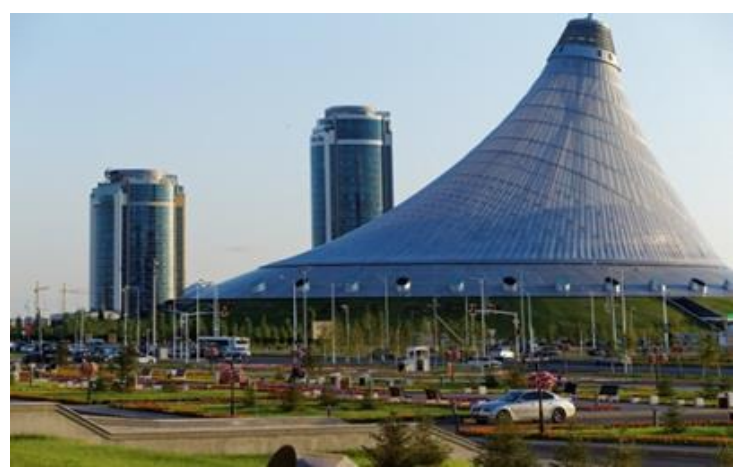

Fig 26. Tensile structure system of Khan Shatyr Entertainment Center, Nur Sultan, Kazakhstan (Source: https://en.wikipedia.org/wiki/Khan_Shatyr_Entertainment_Center\#/media/File:Khan_Shatyr.jpg) 
The fabric roof is constructed from ETFE-cushions provided by Vector Foiltec, suspended on a network of cables strung from a central spire (Figure 27). The transparent material allows sunlight through which, in conjunction with the stack effect, air heating and cooling systems, is designed to maintain an internal temperature between $15-30{ }^{\circ} \mathrm{C}$ in the main space and $19-24{ }^{\circ} \mathrm{C}$ in the retail units, while outside the temperature varies between -35 and $35^{\circ} \mathrm{C}$ across the year (Wikipedia, 2019).

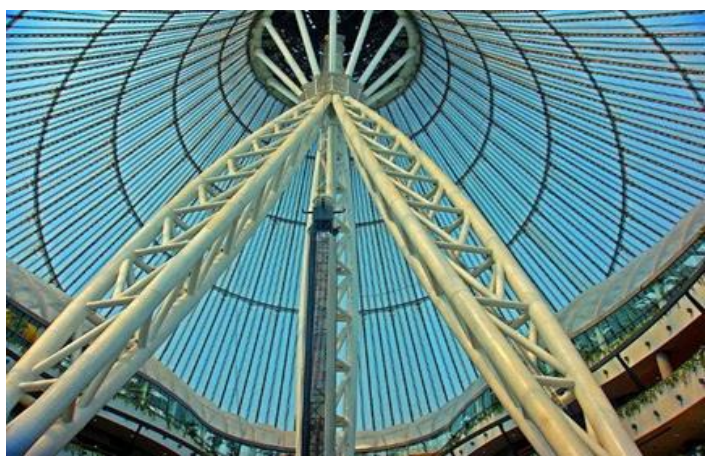

Fig 27. The central mast of Khan Shatyr Entertainment Center, Nur Sultan, Kazakhstan (Source: https://photos.wikimapia.org/p/00/01/35/30/76_big.jpg)

\subsection{Yoyogi National Gymnasium, Tokyo, Japan}

Yoyogi National Gymnasium is an arena located at Yoyogi Park in Shibuya, Tokyo, Japan, which is famous for its suspension roof design. It was designed by Kenzo Tange and built between 1961 and 1964 to house swimming and diving events in the 1964 Summer Olympics by Japan Sports Council (Figure 28). A separate annex was used for the basketball competition at those same games. It will also host handball competitions at the 2020 Summer Olympics. The design inspired Frei Otto's arena designs for the Olympic Stadium in Munich (Palmer, 2009).

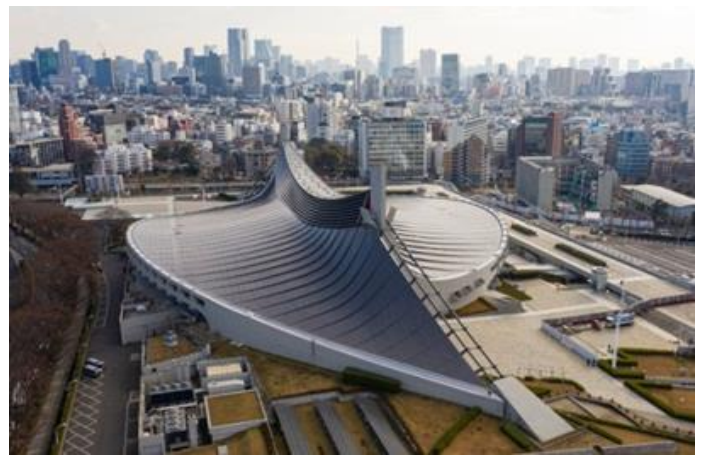

Fig 28. Tensile Structure System of Yoyogi National Gymnasium, Tokyo, Japan (Source: https://commons.wikimedia.org/wiki/File:Kokuritsu_Yoyogi_Ky\%C5\%8Dgij\%C5\%8D_1.jpg)

\section{Conclusion}

Fabric structures represent a new chapter in the history of building structures. Despite its more extensive use over the past decade or so in architectural applications, tension fabric is still a relatively new building material. Discovering necessary forms and amount of pre-stressing can be extremely complex, sometimes only vaguely understood, and therefore much care is taken in designing structures involving this material. The tensile fabric structures are capable of spanning large distances while incurring very little weight on supporting structure, developments in the design of fabric structure can dramatically change the way we conceptualize permanent building construction. However, the advantages of tension fabric cannot be disputed. The design and analysis process is perhaps the most limiting factor in the implementation of fabric structure. Exhibiting highly nonlinear behavior, the behavior of fabric 
under applied loads is often difficult to understand and to model. Beginning with simple fabric models in the days of Frei Otto at the Institute of Lightweight Structures, analysis theories and methods have adapted into complex computational models capable of quickly and accurately determining the form and behavior of a fabric membrane (Fang, 2009).

\section{References}

Armijos, S. J. (2020). Five steps to a fabric structure experience, [Online] Available from http://www.fabricarchitect.com, accessed on 10 June 2020.

Barnes, M. \& Dickson M. (2000), Widespan Roof Structures, Thomas Telford Publishing, London

Birdair (2019), Denver international airport, [Online] Available from https://www.birdair.com/birdairportfolio/denver-international-airport/, accessed on 20 August 2020

Browne, N. (2019) Fabric Architecture and Signature Structures. [Online] Available from www.fabricarchitecture.co.uk/cpd.htm, accessed on 10 May 2020.

Burohappold (2020), 02 Arena and Millennium Dome, Mill [Online] Available from https://www.burohappold.com/projects/millennium-dome/\#, accessed on 28 July 2020.

Fang, R. (2009) The Design and Construction of Fabric Structures, Master of Engineering Thesis, Massachusetts Institute of Technology, USA.

Gandhi, U. (2020) Design and Construction of Tension Membrane Structures. [Online] Available from http://homepages.cae.wisc.edu/ ukgandhi/documents/tensile\%20structures_paper.pdf, accessed on 25 July 2020.

Ishii K; Shin Kenchikusha S., Henshūbu K. (1999). Membrane designs and structures in the world, Shin Kenchikusha Publishers, Tokyo.

Kamal, Arif M. (2016) The Morphology of Tensile Structure Systems, [Online] Available from https://www.masterbuilder.co.in/morphology-tensile-structure-systems/the-morphology-oftensile-1/, accessed on 10 May 2020.

Landrell A. (2019), Famous examples of tensile structures, [Online] Available from www.architen.com/2012/05/famous-examples-of-tensile-structures/, accessed on 15 May 2020.

Mills J. (2010). The Khan Shatyr Entertainment Centre by Foster + Partners, [Online] Available from https://www.dezeen.com/2010/07/06/the-khan-shatyr-entertainment-centre-by-fosterpartners/, accessed on 10 May 2020.

Palmer, A. L. (2009), The A to Z of Architecture. The Scarecrow Press Inc. USA.

Price K. (2015) Practical Aspects of Design and Material Specifications [Online] Available from www.tensionstructures.co.za/tensile-fabric-structures/, accessed on 26 August 2020.

Redskyshelters (2020). The History of Tensile Architecture. Red Sky Shelters. [Online] Available from www.redskyshelters.com/tensilehistory.html, accessed on 25 July 2020.

Seaman, R., \& Bradenburg, F. (2000). Utilization of vinyl coated polyester fabrics for architectural applications. Journal of Industrial Textiles, 30(1), 63-82.

Shaeffer, R. E. (1996) Tensioned Fabric Structures: A Practical Introduction. New York, NY: American Society of Civil Engineers.

Tolani A. N., Patil A. S., Patil G. N., Vadalkar V. H., Barbude P. R. (2016), Advantages of Tensile Structures over other space frame structures, International Journal of Research in Engineering and Technology, 5 (5), 568-575.

Walter, B. (1977) Role of the Fabricator - Large Fabric Structures. ASCE Spring Convention and Exhibit. Dallas, TX: American Society of Civil Engineers.

Weaver M. (2020), Tension Fabric: Wave of the Future [Online] Available from https://illumin.usc.edu/tension-fabric-waves-of-the-future/, accessed on 15 July 2020.

Wikipedia.org. (2019) Tensile Structure, [Online] Available from www.en.wikipedia.org/wiki/Tensile_structure, accessed on 25 August 2020. 
Wikipedia (2020), The 02 [Online] Available from https://en.wikipedia.org/wiki/The_02, accessed on 10 May 2020. 